\title{
The shea(e)r stress of it all
}

\author{
Jan D. Galla, MD, PhD
}

\author{
From Englewood Cardiac Surgery Associates, Englewood Hospital Medical Center, Englewood, NJ. \\ Disclosures: Author has nothing to disclose with regard to commercial support. \\ Received for publication Dec 8, 2017; accepted for publication Jan 31, 2018; available ahead of print Feb 28 , \\ 2018. \\ Address for reprints: Jan D. Galla, MD, PhD, Englewood Cardiac Surgery Associates, 350 Engle St, Suite 5200, \\ Englewood, NJ 07631 (E-mail: Jan.Galla@ehmchealth.org). \\ J Thorac Cardiovasc Surg 2018;155:2287-8 \\ $0022-5223 / \$ 36.00$ \\ Copyright (c) 2018 by The American Association for Thoracic Surgery \\ https://doi.org/10.1016/j.jtcvs.2018.01.065
}

We don't have enough stress in daily practice? Scrounging cases, assuaging referrals, achieving quality benchmarks, repairing torn vessels and chambers, bloodless surgery, the porcelain aorta-the list is endless, or so we thought. Now, in this issue of the Journal, Bollache and colleagues, ${ }^{1}$ using 4-dimensional (4D) magnetic resonance imaging (MRI), investigate aortic wall shear stress patterns and the effect of various surgical interventions on these patterns.

Why should we be concerned about aortic wall shear stress? Consciously or subconsciously, we all recognize pressure and volume/flow effects on the aortic wall; think management (both operative and medical) of aortic dissection, poststenotic dilatation of the ascending aorta, and primary closure of an aortotomy or reinforcement with pericardium/felt/Dacron. A quick search of the literature for the last several years shows numerous examples of aortic wall shear stress analyses at the basic science ${ }^{1-3}$ and clinical levels, both adult ${ }^{4-6}$ and pediatric. ${ }^{7,8}$ In addition, wall shear stress analyses related to valve morphology/pathology, 5,9 including some using a similar 4D MRI technique, ${ }^{10,11}$ have begun to elucidate the effects of valve disease on aortic structure. These studies suggest that the interest in the effects of flow patterns and forces on aortic wall morphology is not only increasing, and increasing our understanding about how aortic shaping, deformity, and pathologies arise, but is also more easily studied with the application of latest-generation imaging methodologies.

In the present study, the authors, in a limited number of patients $(n=33)$, examine the effects of various aortic valve replacement and aortic root reconstruction procedures on wall shear stress patterns of the residual aorta. As a control, a series of unoperated patients was followed for comparison. Unsurprisingly, the control group showed little change in wall shear stress measurements over time, despite having a notably different follow-up interval, whereas significant changes in wall shear stress patterns were seen following interventions. As might be intuitively expected, proximal aortic wall shear stress patterns were diminished following aortic valve replacement, despite a wide range of valve sizes (23-29 mm) and types (3 different pericardial, 1 mechanical) used. Interestingly, aortic wall shear stress values

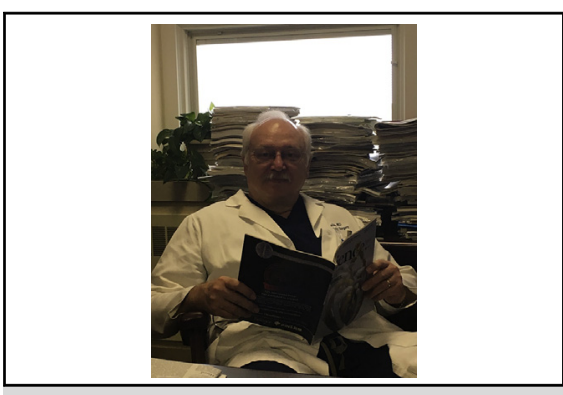

Jan D. Galla, MD, PhD

Central Message

The use of 4-dimensional MRI imaging to evaluate the role of wall shear stress in aortopathy and therapeutic interventions represents an evolution in our understanding of aortic flow dynamics.

See Article page 2277.

increased distal to grafts when aortic root reconstructions were performed. Whether this was from the graft size or manufacturing characteristics was not analyzed, but it might be speculated that compliance and subsequent flow dynamic changes from a synthetic to biological (ie, graft to aorta) conduit might explain these findings. Moreover, few differences in wall shear stress patterns were seen between hemi-arch and ascending aortic reconstructions. Again, this might be explained by a "softening" or "buffering" effect of native aortic tissue as opposed to a more noncompliant conduit.

It is somewhat unfortunate that a more detailed analysis of the effects of the varied valve types and sizes, either separately (as in AVR) or fashioned into conduit, or of a valvesparing procedure, again either with or without conduit, could not be done, given the small size of the series and thus the insufficient amount of meaningful data that could be derived. A similar yearning for analyses of the varied aortic reconstructive techniques follows; however, these results are an extension of this group's previous reporting using the 4D MRI imaging technique, ${ }^{12}$ and one might expect that as their database grows, further insight into shear stress effects, from both pathology and any gained relief from therapeutic interventions, will be forthcoming. Hopefully, the knowledge gained from these analyses will allow tailoring of therapies to maximally reduce wall shear stresses to preserve aortic wall strength, configuration, and ultimately patient well-being. 
With increasing understanding of the combination of turbulence and flow dynamics effects (wall shear stress) on the aortic wall, appropriately guided therapies for either corrective or preventive measures will quickly follow. The shee(a)r stress of waiting for direction might otherwise get to us all.

\section{References}

1. Bollache E, Fedak PWN, van Ooij P, Rahman O, Malaisrie SC, McCarthy PM, et al. Perioperative evaluation of regional aortic wall shear stress patterns in patients undergoing aortic valve and/or proximal thoracic aortic replacement. J Thorac Cardiovasc Surg. 2018;155:2277-86.e2.

2. Mahmoud MM, Serbanovic-Canic J, Feng S, Souihol C, Xing R, Hsiao S, et al. Shear stress induces endothelial-to-mesenchymal transition via the transcription factor Snail. Sci Rep. 2017;7:3375.

3. Li X, Yang Q, Wang Z, Wei D. Shear stress in atherosclerotic plaque determination. DNA Cell Biol. 2014;33:830-8.

4. Assmann A, Ful F, Benim AC, Joos F, Akhyari P, Lichtenberg A. Dispersive aortic cannulas reduce aortic wall shear stress affecting atherosclerotic plaque embolization. Artif Organs. 2014;39:203-11.

5. Chi Q, He Y, Luan Y, Qin K, Mu L. Numerical analysis of wall shear stress in ascending aorta before tearing in type A aortic dissection. Comput Bio Med. 2017;89:236-47.
6. Mahadevia R, Barker AJ, Schnell S, Entezari P, Kansal P, Fedak PW, et al. Bicuspid aortic cusp fusion morphology alters aortic three-dimensional outflow patterns, wall shear stress, and expression of aortopathy. Circulation. 2014;129: 673-82.

7. Osswald A, Karmonik C, Anderson JR, Rengier F, Karck M, Engelke J, et al. Elevated wall shear stress in aortic type B dissection may relate to retrograde aortic type A dissection: a computational fluid dynamics pilot study. Eur J Vasc Endovasc Surg. 2017;54:324-30.

8. Fukui T, Asama H, Kimura M, Itoi T, Morinishi K. Influence of geometric changes in the thoracic aorta due to arterial switch operations on the wall shear stress distribution. Open Biomed Eng J. 2017;11:9-16.

9. Miyazaki S, Miyaji K, Itatatni K, Oka N, Goto S, Nakamura M, et al. Surgical strategy for aortic arch reconstruction after the Norwood procedure based on numerical flow analysis. Interact Cardiovasc Thorac Surg. 2018;26:10-1.

10. Ha H, Koo HJ, Lee JG, Kim GB, Kweon J, Lee SJ, et al. Association between flow skewness and aortic dilatation in patients with aortic stenosis. Int J Cardiovasc Imaging. 2017;33:1969-78.

11. van Ooij P, Markl M, Colllins JD, Carr JC, Rigsby C, Bonow RO, et al. Aortic valve stenosis alters expression of regional aortic wall shear stress: new insights from a 4-dimensional flow magnetic resonance imaging study of 571 subjects. $J$ Am Heart Assoc. 2017;6:e005959.

12. Piatti F, Sturla F, Bissel MM, Pirola S, Lombardi M, Nesteruk I, et al. 4D flow analysis of BAV-related fluid-dynamic alterations: evidence of wall shear stress alterations in absence of clinically relevant aortic anatomical remodeling. Front Physiol. 2017;8:1-17. 